\title{
Contribution of desiccation to monotonic and cyclic strength of thickened gold tailings - not the same as over-consolidation
}

\author{
F. Daliri Carleton University, Canada \\ H. Kim Carleton University, Canada \\ P. Simms Carleton University, Canada
}

S. Sivathayalan Carleton University, Canada

\section{Abstract}

In many jurisdictions, regulators are concerned with remobilisation of high unbounded deposits of mine waste residuals, such as thickened tailings stacks. Consequently, the monotonic and cyclic behaviour of thickened tailings is of significant interest to practitioners of mine waste geotechnique. Thickened tailings are known to gain strength through a combination of hindered settling, desiccation, and consolidation postdeposition. This paper reports on the effects of over-consolidation ratio (OCR) and desiccation, investigated using a simple shear apparatus (NGI type). Samples for element testing were obtained from laboratory tests simulating multilayer deposition in columns or flumes. In each test, tailings were deposited at some initial solids concentration and allowed to desiccate to different values of water content, both above and below the shrinkage limit. These tailings were then overlaid with fresh tailings, and allowed to resaturate by capillary action from the fresh layer. Tailings from the bottom layer were then extracted using thin-wall Shelby tube. Some tailings were allowed to settle, subsequently extracted with no desiccation, and mechanically over-consolidated. Very sharp differences in both the quantitative and qualitative behaviours of samples prepared by these two methods were observed. Mechanically over-consolidated samples exhibited high peak strengths, whereas desiccated samples exhibited much lower strengths at phase transformation, but substantial strain hardening past phase transformation. This information is very important to geotechnical practitioners working on thickened tailings projects, as many operate under the assumption that desiccation is analogous to mechanical over-consolidation.

\section{Introduction}

Cycling deposition between a number of spigots allows for tailings to densify due to desiccation and/or drainage, supplementing consolidation as a mechanism for strength gain. One potential advantage of this practice is that the tailings are in some sense over-consolidated by desiccation, resulting in an increase in strength and improved stability during earthquakes. However, research on exactly how desiccation contributes to strength has been limited to a few studies (Cifuentes and Verdugo, 2009; Al-Tarhouni et al., $2009,2011)$. This paper attempts to quantify the contribution of desiccation to strength, and to compare the shear strength behaviour of the tailings to those mechanically over-consolidated to reach similar density.

The role of desiccation should be considered in the context of the overall stress history of a layer of tailings. This stress history will vary with the climate, deposition sequencing or 'drying time', and layer thickness. Figure 1 shows a possible volume-stress history of a thickened tailings layer, which initially has a decrease in volume due to settlement of tailings particles under gravity. In the next step, the tailings layer shrinks due to drying, is subsequently rewetted by the placement of a top layer, and then undergoes consolidation as other layers are deposited. During desiccation, the thickened tailings (TT) layer experiences a stress history dependent on the drying time and evaporation rate. Continuing desiccation to different values of 
water contents leads to generation of different values of matric suction and different void ratios, which both influence the monotonic and cyclic response of the layer, even after burial by new tailings. While others have examined how to estimate the degree of desiccation that occurs for a given deposition scheme in a given climate (Fisseha et al., 2010; Simms et al., 2010), this paper examines how varying desiccation, in terms of water content, influences strength.

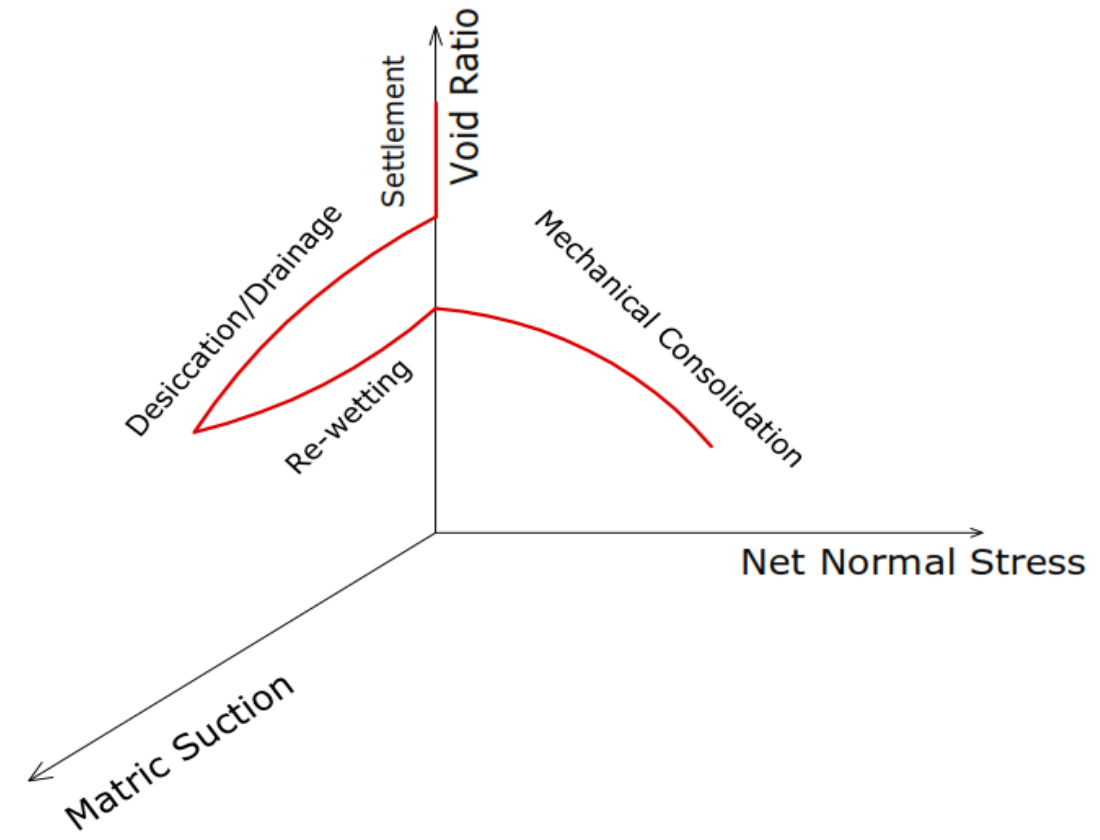

Figure 1 A possible volume-stress history of a thickened tailings layer post-deposition

The specific objectives of this paper can be summarised as:

- To simulate the stress history that occurs in the field in laboratory specimens, to facilitate shear strength testing using a NGI simple shear device. This objective concentrates on the effect of degree of desiccation on monotonic and cyclic shear response of thickened gold tailings.

- To examine how comparable over-consolidation is due to desiccation to mechanical overconsolidation.

This paper supplements the line of investigation started by Al-Tarhouni et al. $(2009,2011)$ and continued by Kim et al. (2011) and Daliri et al. (2011).

\section{$2 \quad$ Materials and methodology}

Gold tailings were transported from the mine submerged in water-filled plastic bags - in order to minimise oxidation of the minerals and acid generation. Although the tailings were shipped at the pumping water content (38\% geotechnical gravimetric water content), it was found that due to agitation during transport, the water content reduced to around $22-25 \%$ and it was necessary to remix the tailings with the bleed water produced by settling in order to reproduce tailings with a water content of $38 \%$. These tailings would then settle to a water content of $30-32 \%$ within 48 hours, even for thin $(<10 \mathrm{~cm})$ layers. The specific gravity of the tailings was 2.89 ; the liquid limit $\left(w_{L}\right)$, plastic limit $\left(w_{p}\right)$, and shrinkage limit were $22.5,20$, and 19 respectively.

The soil-water characteristic curve (SWCC - also called the water-retention curve, WRC) was determined as per standard methods, with the additional measurement of volume change (Fisseha et al., 2010). For matric suctions lower than $400 \mathrm{kPa}$, an axis-translation pressure plate was used. For larger suctions, the sample was removed from the axis-translation device and dried in the open air, and small samples $(<20 \mathrm{~g})$ were regularly removed and tested for total suction and then oven-dried to obtain the points at higher suctions. 
The important aspect of the SWCC for this study is the air-entry value (AEV), the point at which significant desaturation starts to occur. In other words, the AEV is reached when the decrease in the mass of water is no longer the same as the decrease in volume. This point occurs at approximately $70 \mathrm{kPa}$, or $22 \%$ water content. The AEV here is defined by the intercept of the slope of the SWCC at low suctions $(<100 \mathrm{kPa})$ with the slope of the SWCC after the AEV (from about 100 to 1,000 kPa). The AEV is important to stress history, since as the degree of saturation decreases, the contribution of matric suction to effective stress, and therefore to the stress history of the tailings, also decreases.

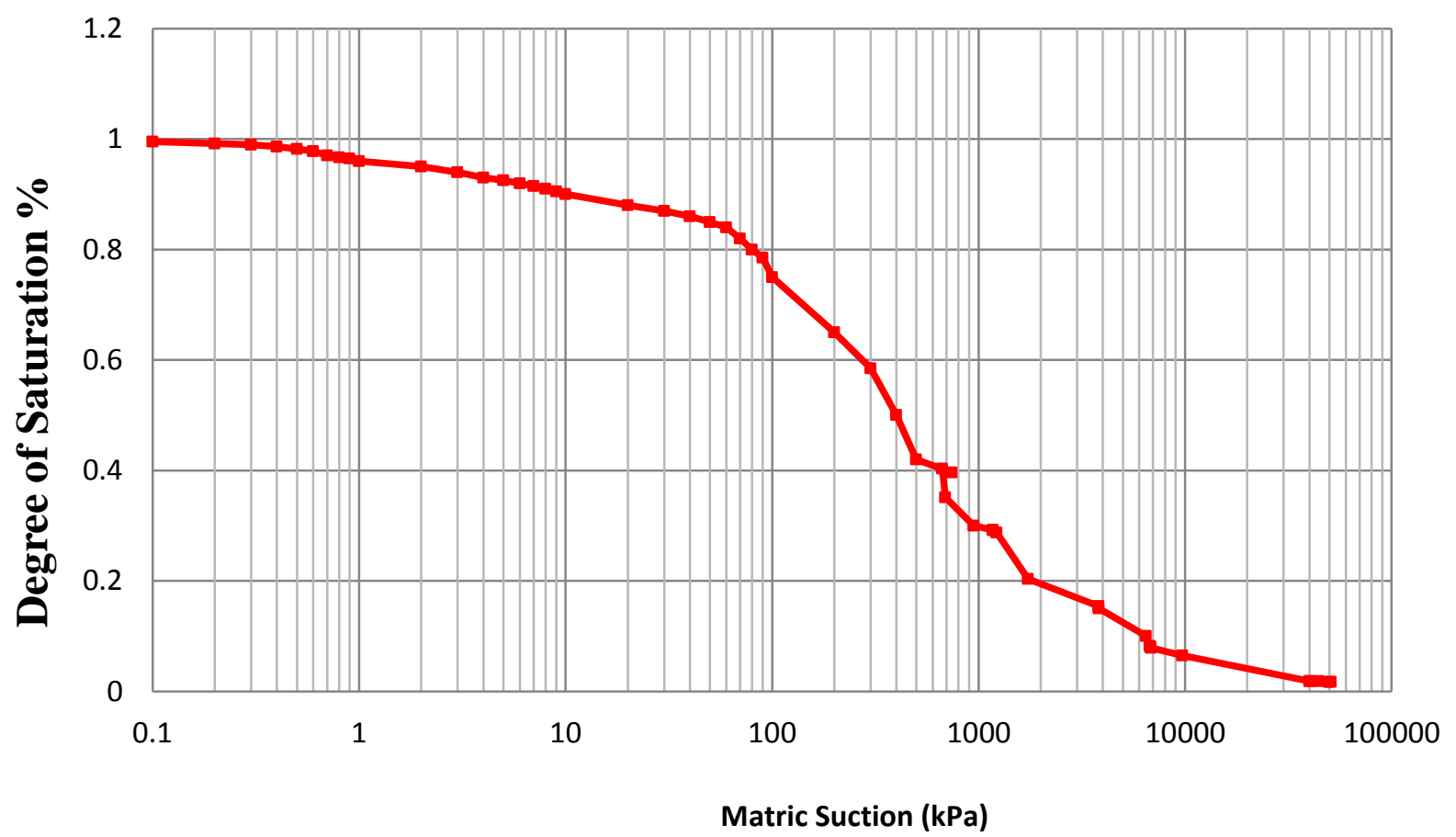

Figure 2 Soil-water retention curve of gold tailings placed at water content of $38 \%$

To simulate field stress history, the methodology of two layers of tailings with a thickness of about $10 \mathrm{~cm}$ were successively deposited in a cylindrical column with a $25 \mathrm{~cm}$ diameter. The first layer of thickened tailings were deposited in the column at pumping water content (38\%) and allowed to desiccate to different values of water content, above $(30,28,25$, and $23 \%)$ and below $(19,17,12$, and $4 \%)$ the AEV. Figure 3 presents the behaviour of deposited tailings at different values of water contents during desiccation. For samples desiccated past $w=16 \%$, cracks were generated. Desiccated tailings were then overlaid with fresh tailings $(w=38 \%)$, which led to resaturation of the underlying tailings by flow of water under gravity or capillary action. Extracted samples were obtained from the bottom layer after about 12 hours. The water content of the samples at extraction consistently fell in the range between $21-22 \%$, with degrees of saturation $>90 \%$. For extracting sampling, thin wall tubes with the length-diameter ratio of 1.42 were utilised. Extracted samples were placed in a simple shear device and consolidated under consolidated pressures of $50 \mathrm{kPa}, 100 \mathrm{kPa}$ or $200 \mathrm{kPa}$. 


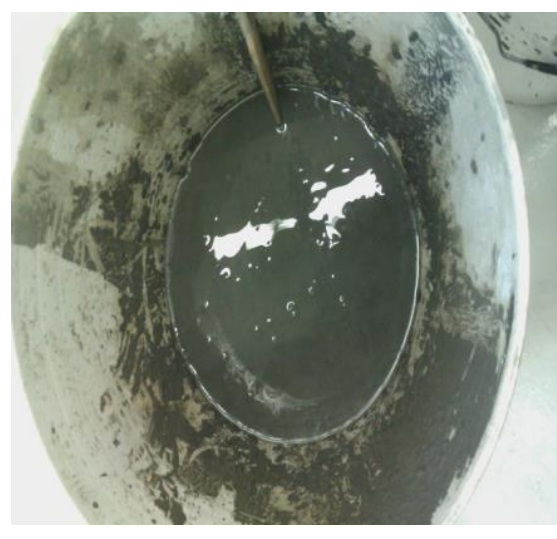

(a)

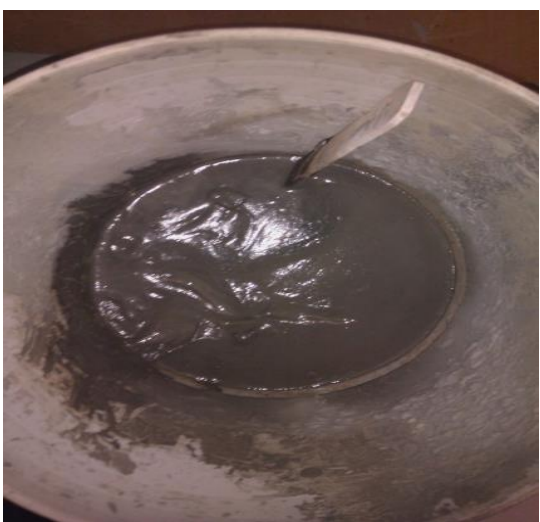

(b)

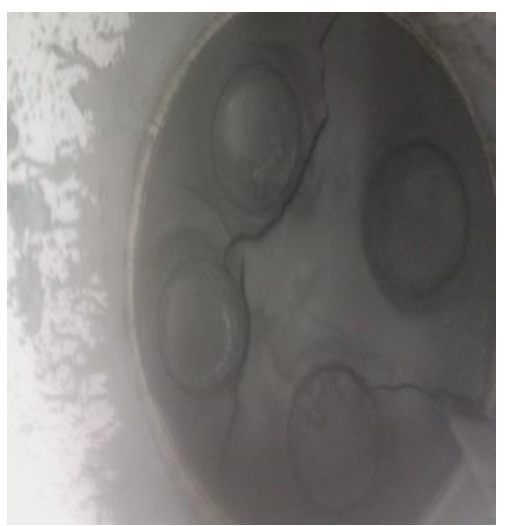

(c)

Figure 3 Behaviour of the deposited tailings during desiccation (a) $w=38 \%, \quad$ (b) $w=27 \%, \quad$ (c) $\mathrm{w}=16 \%$

In order to quantify the process of desiccation-rewetting-consolidation (i.e. stress history), Equation (1) is introduced:

$$
\text { OCRD }=\frac{\text { Maximum Suction Stress During Desiccation }}{\text { Maximum effective consolidation pressure }}
$$

'Suction stress' is the contribution for matric suction to effective stress. For suctions less than the AEV, the suction stress is equal to suction. Above the AEV the relation between suction and suction stress is complex. Readers are referred to Bishop (1959) and Fredlund and Morgenstern (1977) for different viewpoints on how matric suction contributes to effective stress. We have therefore adopted a simple formulation, namely that suction stress $=$ matric suction $\times$ degree of saturation, which has been adopted by others (Lu and Lukos, 2006) for different applications.

The simple shear apparatus employed in this study was the NGI (Norwegian Geotechnical Institute) type (Figure 4). The use of this device for thickened tailings is described in Al-Tarhouni et al. (2011). 


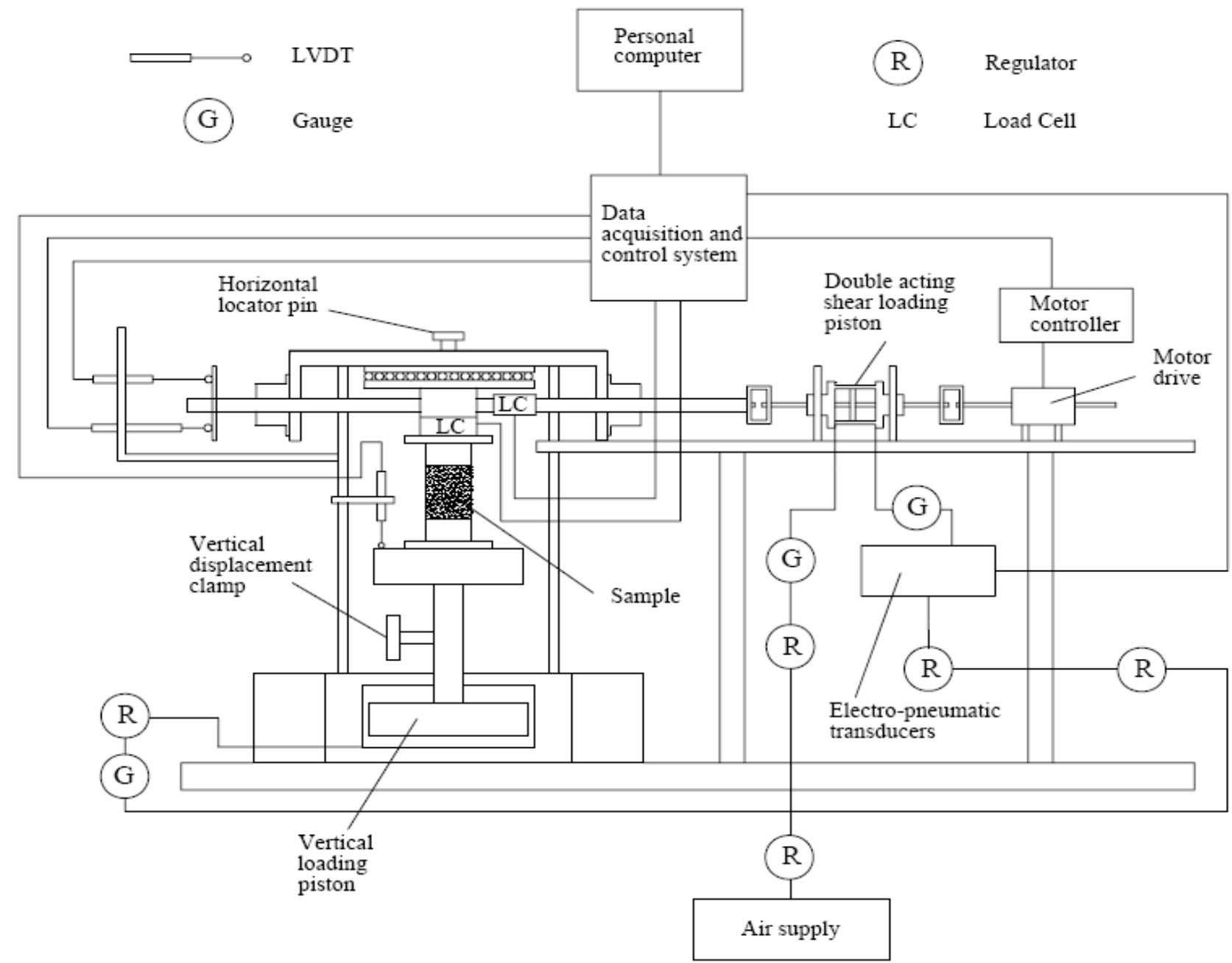

Figure 4 A schematic diagram of the simple shear apparatus (Al-Tarhouni et al., 2011)

\section{$3 \quad$ Results}

\section{1 Monotonic results of desiccated/rewetted samples}

Figure 5 presents the monotonic results of the desiccated/rewetted samples under $50 \mathrm{kPa}$ effective consolidation pressure $\left(\sigma_{v}^{\prime}=50 \mathrm{kPa}\right)$. The symbol $w_{d}$ denotes the water content of the sample after desiccation but before placement of the next layer. It is clear that the sample for $w_{d}=30 \%$, which corresponds to a sample that experienced settling but no desiccation, has a contractive response. As the degree of desiccation becomes higher, the samples become increasingly dilative. With continuing desiccation past the $A E V$, of which the first point corresponds to $O C R_{D}=1.7$, the dilative response increases significantly. Desiccation beyond the AEV continues to increase the dilative response; however, the rate of increase is lower in comparison to samples desiccated to the AEV. The desiccated/rewetted samples were also consolidated to $100 \mathrm{kPa}$ and $200 \mathrm{kPa}$ in addition to $50 \mathrm{kPa}$. Figure 6 presents the comparison of the normalised shear stress at phase transformation (PT) points $\left(\tau_{P T} / \sigma_{v c}^{\prime}\right)$ for different effective consolidation pressures. Phase transformation corresponds to a change from contractive to dilative behaviour. With increasing desiccation to the AEV, the shear stress at PT increases rapidly; however, the rate of increase in shear stress at PT is not as tangible for samples desiccated beyond the AEV. It should be noted that samples with higher consolidation pressures had higher shear stress at PT. 


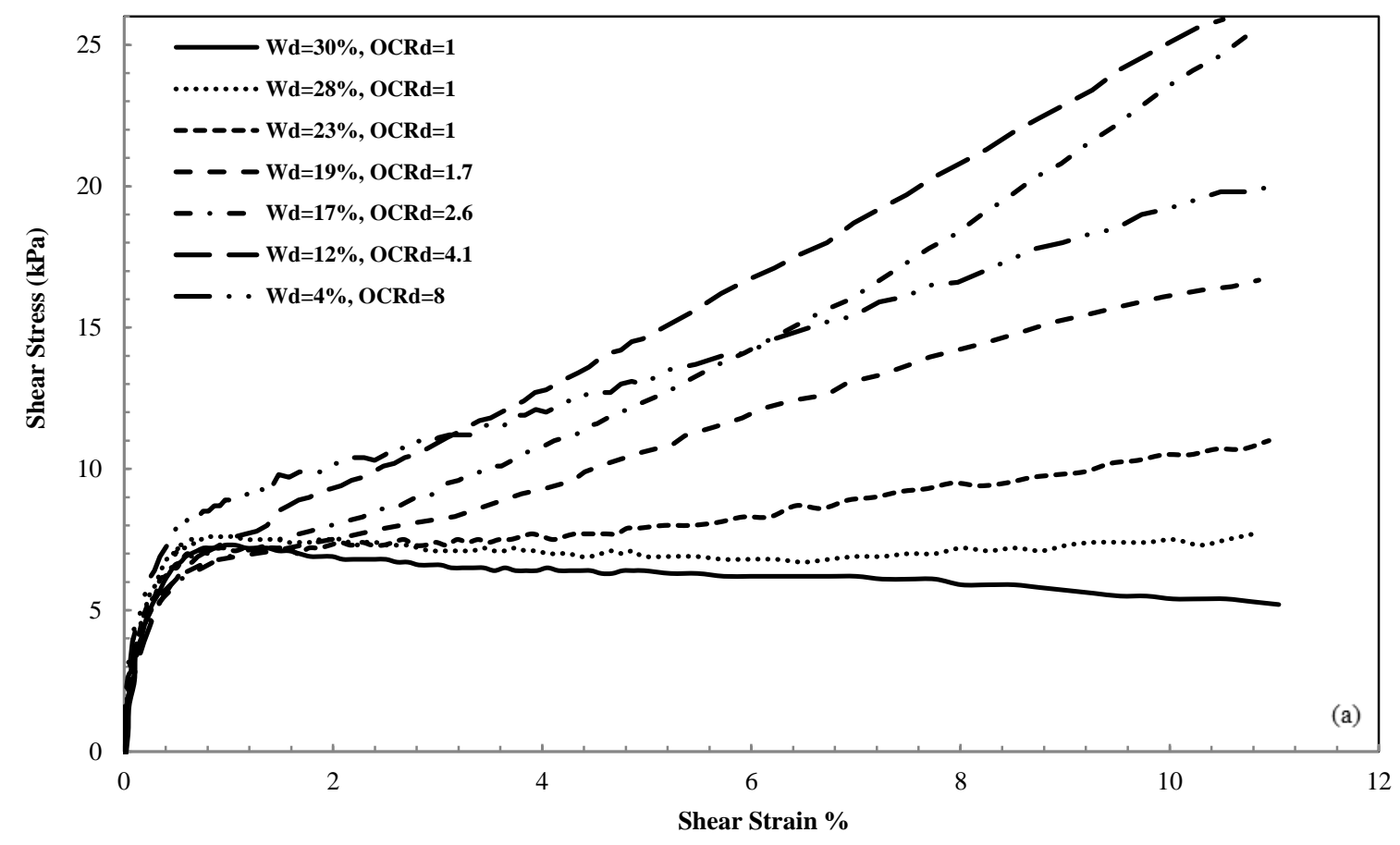

Figure 5 Monotonic results of desiccated/rewetted samples for different degrees of desiccation

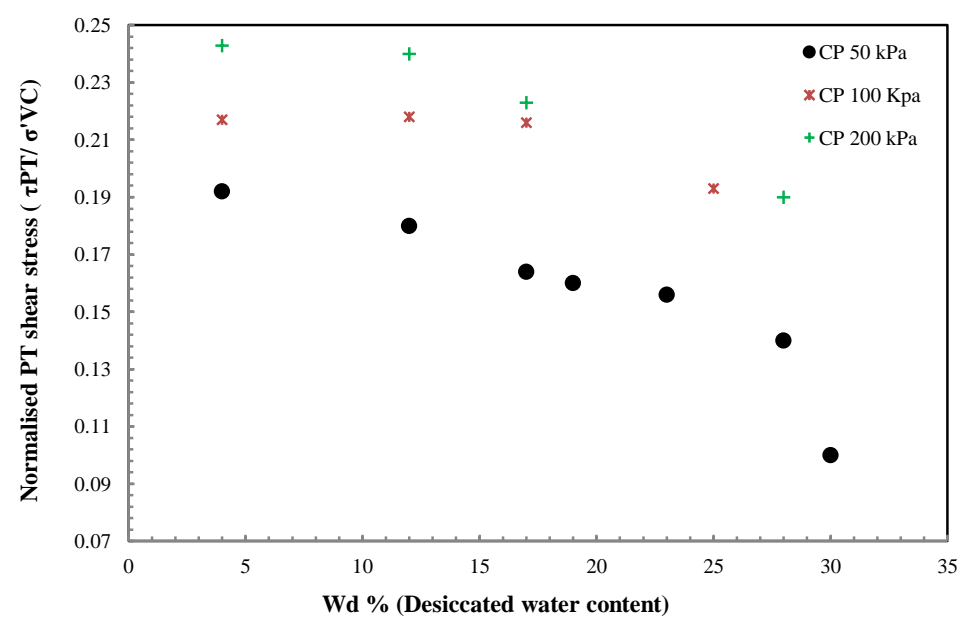

Figure 6 Comparison of the normalised shear stress at phase transformation (PT) points of desiccated/rewetted samples

The volume change stress history of samples desiccated to $w=12 \%$, rewetted and consolidated to $50 \mathrm{kPa}$ is presented in Figure 7. According to Figure 7, desiccation of the deposited layer was continued to $w=12 \%$, which resulted in generation of around $200 \mathrm{kPa}$ suction stress. The final void ratio $\left(\mathrm{e}_{\mathrm{c}}\right)$ after rewetting and consolidation processes was found to be 0.63 . 


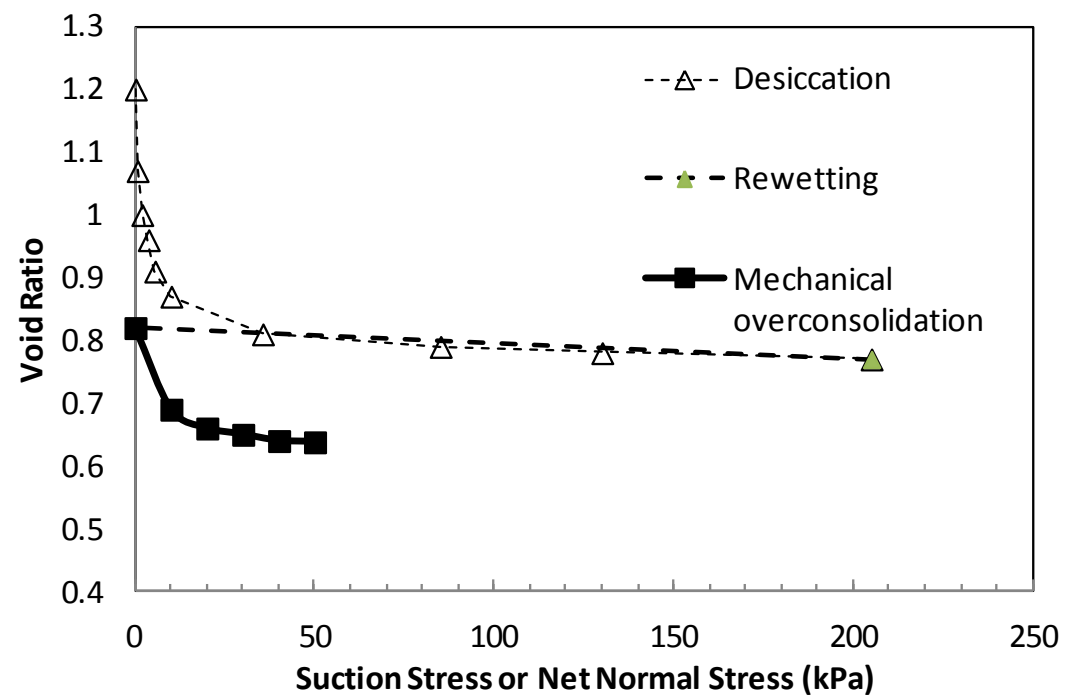

Figure 7 Volume change and stress history of tailings desiccated to $w_{d}=12 \%$

\section{2 Cyclic results of desiccated/rewetted samples}

The cyclic behaviour of specimens with different stress or desiccation history is compared in this section. All cyclic tests were conducted using stress controlled loading at a frequency of $0.1 \mathrm{~Hz}$. The liquefaction criterion suggested by the US National Research Council (NRC, 1985) was adopted: specimens were deemed to have liquefied when single amplitude shear strain exceeded 3.75\%.

Samples with different degrees of desiccation, but consolidated to $50 \mathrm{kPa}$ effective consolidation stress, were tested under different cyclic stress ratios (CSR) i.e. 0.65, 0.075, 0.09, 0.1, 0.11, 0.125, 0.13 and 0.14. CSR in this paper refers to the ratio of the applied cyclic shear stress to the current consolidation pressure (i.e. $\mathrm{CSR}=\frac{\tau_{c y c}}{\sigma_{v c}^{\prime}}$ ). For instance, applying $5 \mathrm{kPa}$ cyclic shear stress on $50 \mathrm{kPa}$ consolidated sample leads to CSR $=0.1$. The program stops applying cyclic shear stress as soon as the generated shear strain exceeds $\gamma=3.75 \%$, which corresponds to liquefaction. The numbers of cycles required to reach liquefaction is designated $\mathrm{N}_{\mathrm{L}}$.

Figure 8 compares excess pore pressure generation of specimens with different desiccation histories. The sample with no desiccation $\left(w_{d}=32 \%\right.$ ) required a lower number of cycles to reach liquefaction. In fact, the rate of pore pressure generation in the sample with no desiccation was significantly faster in comparison to samples with higher desiccation history. It is also illustrated that increasing desiccation history from $\mathrm{W}_{d}=17 \%$ (close to $\mathrm{SL}$ ) to $\mathrm{W}_{d}=12 \%$ somewhat further reduced the rate of pore pressure generation. This behaviour is repeated at other cyclic stress ratios. 


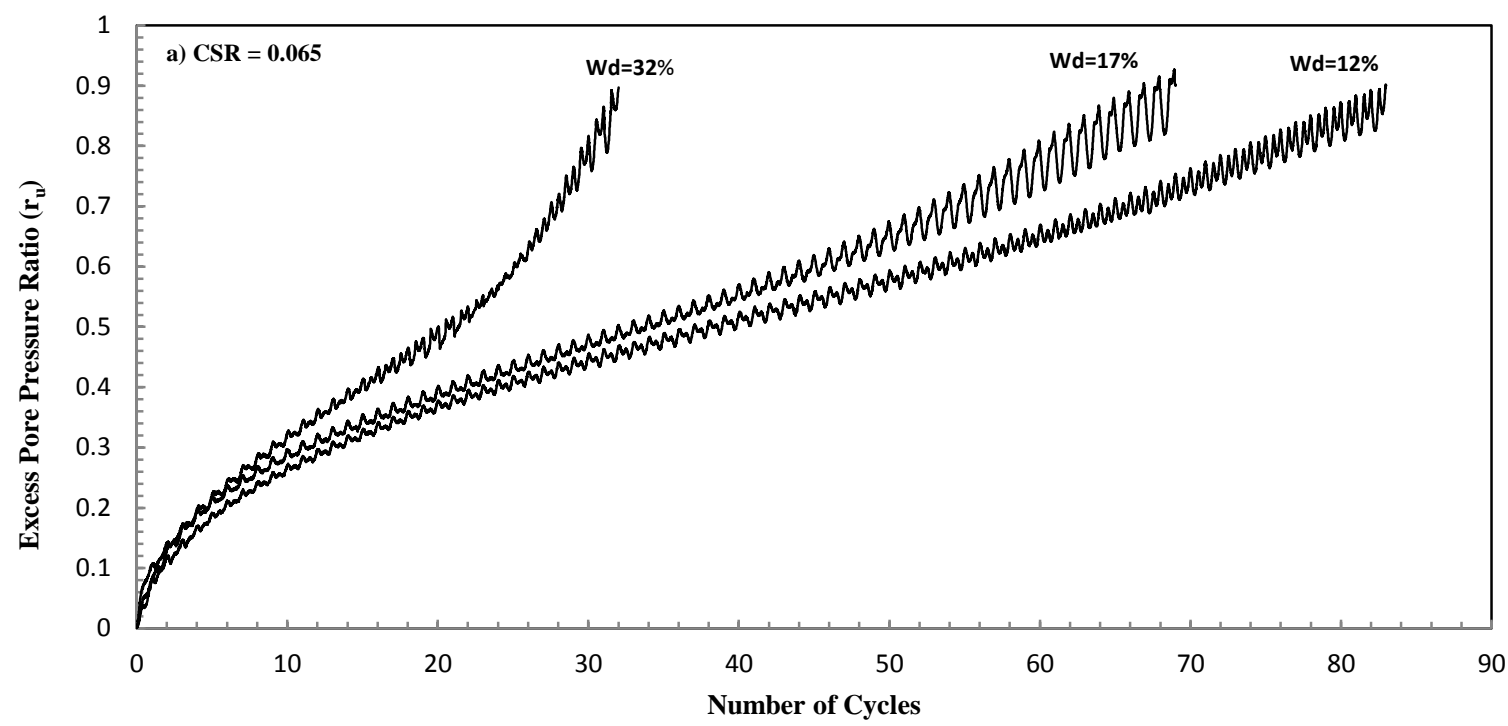

Figure 8 The effect of desiccation history on excess pore water pressure generation of desiccated/rewetted samples

Figure 9 presents the CRR (cyclic resistance ratio) of all desiccated/rewetted samples. Samples with no desiccation $\left(\mathrm{W}_{d}=32 \%\right.$ ) have lower cyclic resistance ratios. Increasing desiccation to $\mathrm{W}_{d}=20 \%$, which is a point close to the AEV (22\%), dramatically increases the cyclic resistance. Continuing desiccation beyond the AEV also increases the CRR curve; however, the rate of increase is not as influential as desiccation to AEV. Figure 10 presents the values of CRR10 and CRR15 versus desiccation history, which correspond to earthquake magnitudes $M_{w}=7$ and $M_{w}=7.5$ respectively. It is shown that similar to monotonic results, desiccation to AEV is beneficial in increasing the CRR. However, increasing desiccation beyond the shrinkage limit also increases the CRR but to a significantly smaller degree compared to the increase up to the AEV.

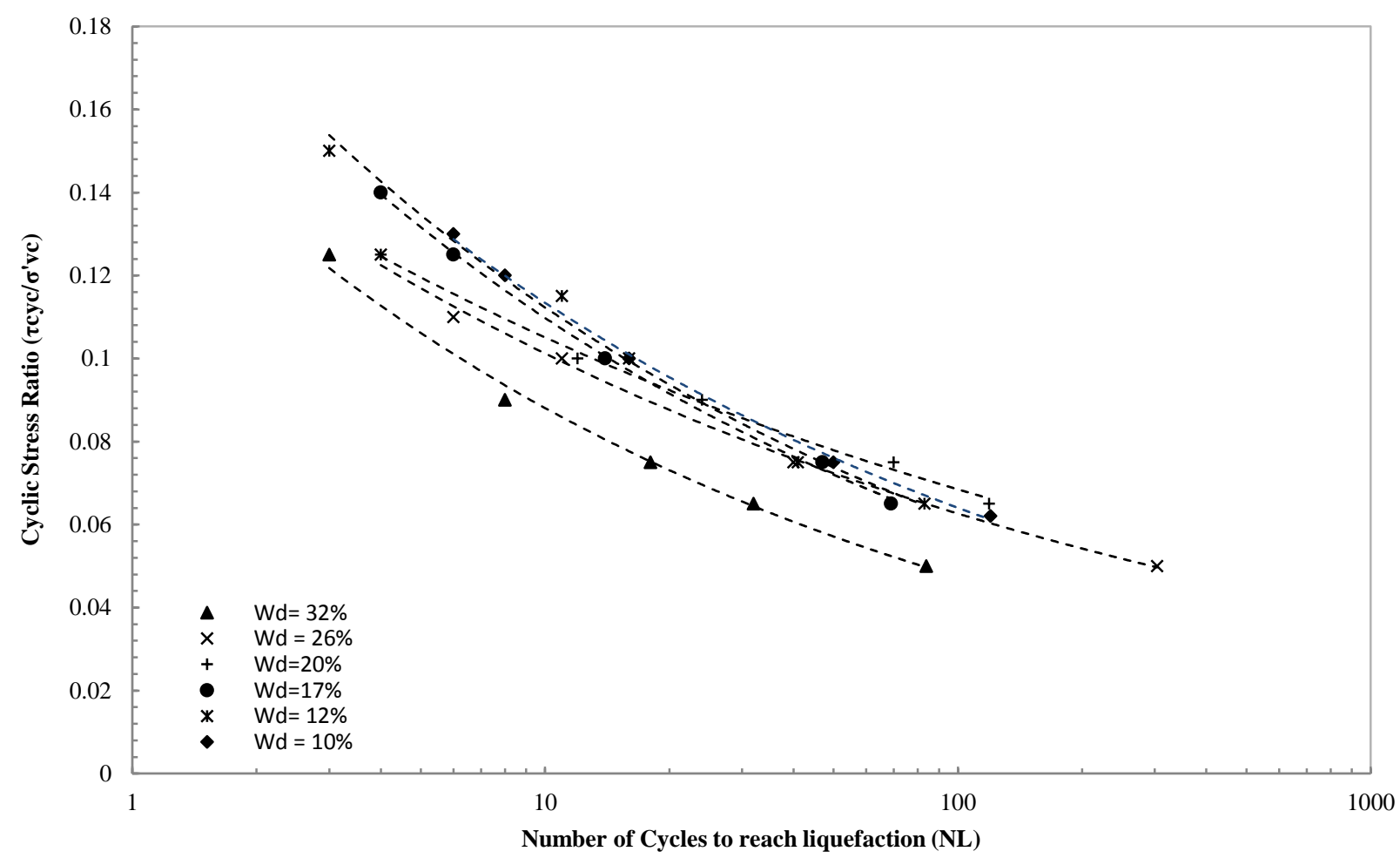

Figure 9 CRR curves for desiccated/rewetted samples 

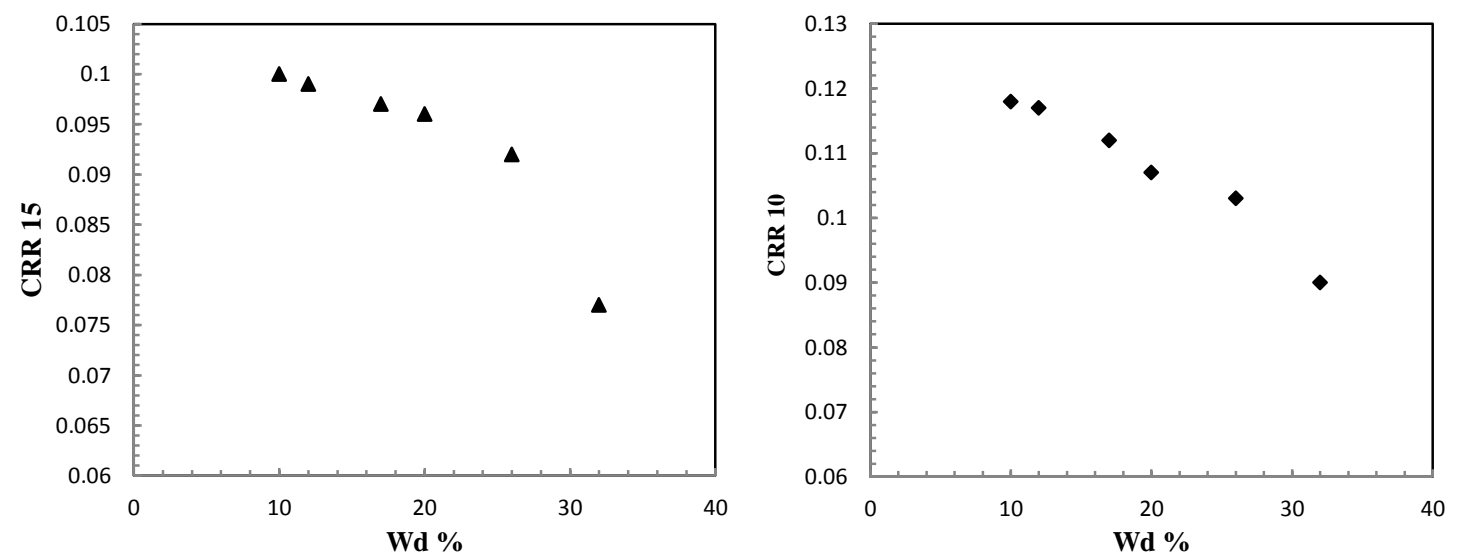

Figure 10 Variation of CRR10 and CRR15 with desiccation history for desiccated and rewetted samples

\section{3 Comparison of mechanically over-consolidated samples with desiccated/rewet samp les}

Mechanically over-consolidated samples were prepared at the pumping water content, allowed to settle, consolidated to 100,200 , or $400 \mathrm{kPa}$ in the simple shear device, and then unloaded to $50 \mathrm{kPa}$ before shearing. Figure 11 presents the monotonic response of samples with mechanical over-consolidation ratio from $O C R_{M}=1$ to $O C R_{M}=8$, along with desiccated samples for comparison. Normally consolidated tailings at $27 \%$ water content exhibited limited liquefaction type of response. Increasing OCRM had a significant effect on the stress path and stress strain responses, and the behaviour transformed to be more dilative as $\mathrm{OCR}_{M}$ increased. Tailings with $\mathrm{OCR}_{M}=2$ showed fairly similar characteristics as normally consolidated tailings, but exhibited higher shear resistance. Tailings with OCRM of 4 and 8, on the other hand, showed strain hardening behaviour. The results clearly demonstrate that the mechanical over-consolidation (OCRM) is more influential on the monotonic response of thickened gold tailings than over-consolidation ratio derived by desiccation.

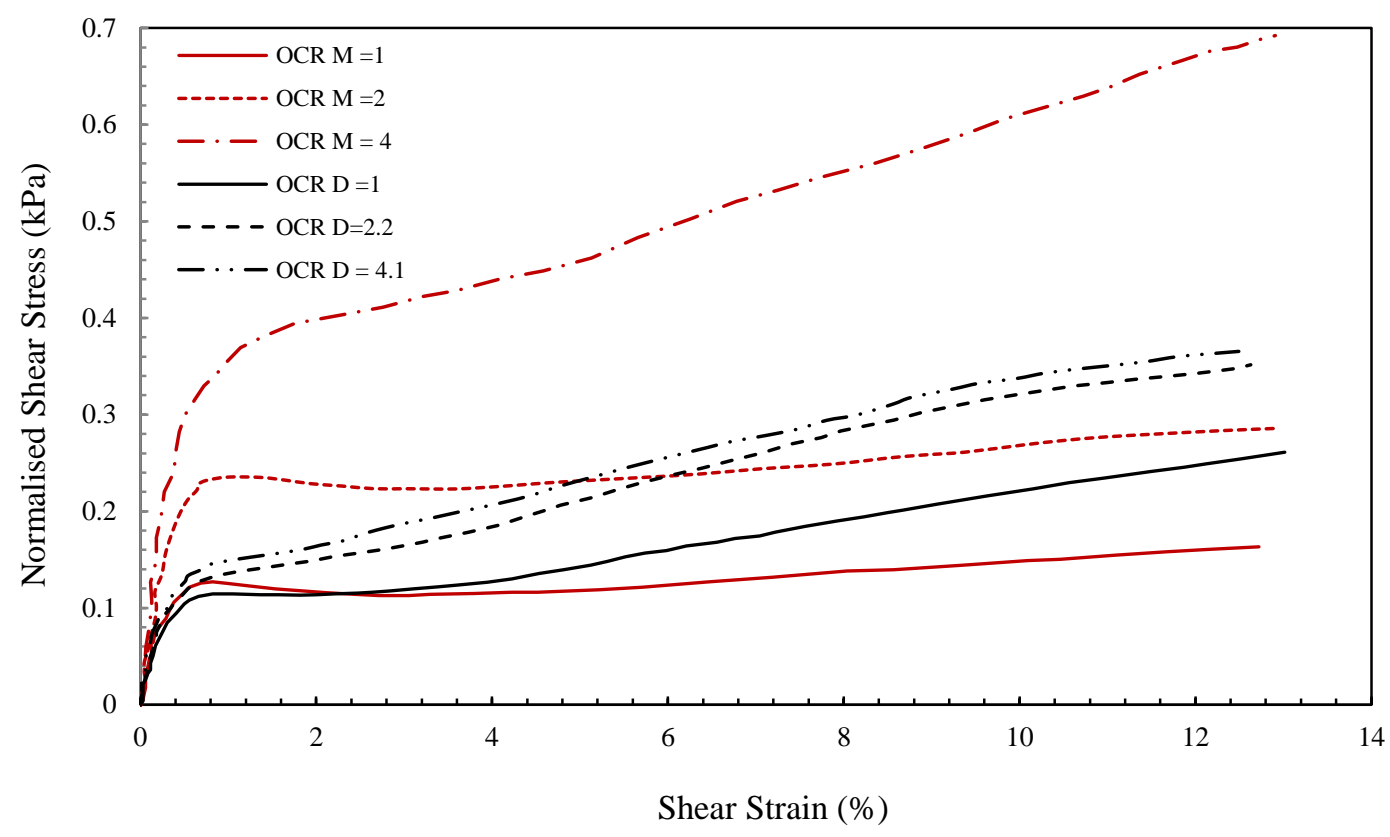

Figure 11 Comparison of monotonic results of mechanical over-consolidated and desiccated rewet samples for $50 \mathrm{kPa}$ consolidation pressure

Figure 12 presents the CRR curves at different mechanical OCRs along with the desiccated samples. It is clearly observed that the number of cycles to reach liquefaction $\left(\mathrm{N}_{\llcorner}\right)$is significantly higher in higher OCRM. 
For instance, samples with $\mathrm{OCR}_{M}=2$ required around 4 cycles to reach liquefaction under $\mathrm{CSR}=0.2$, and that at $O C R_{M}=4$ and $O C R_{M}=8$ required 16 and 66 cycles respectively at the same CSR. The equivalent stress cycles produced by earthquakes are typically in the range of 5 to 25 (depending on the magnitude of the earthquake).

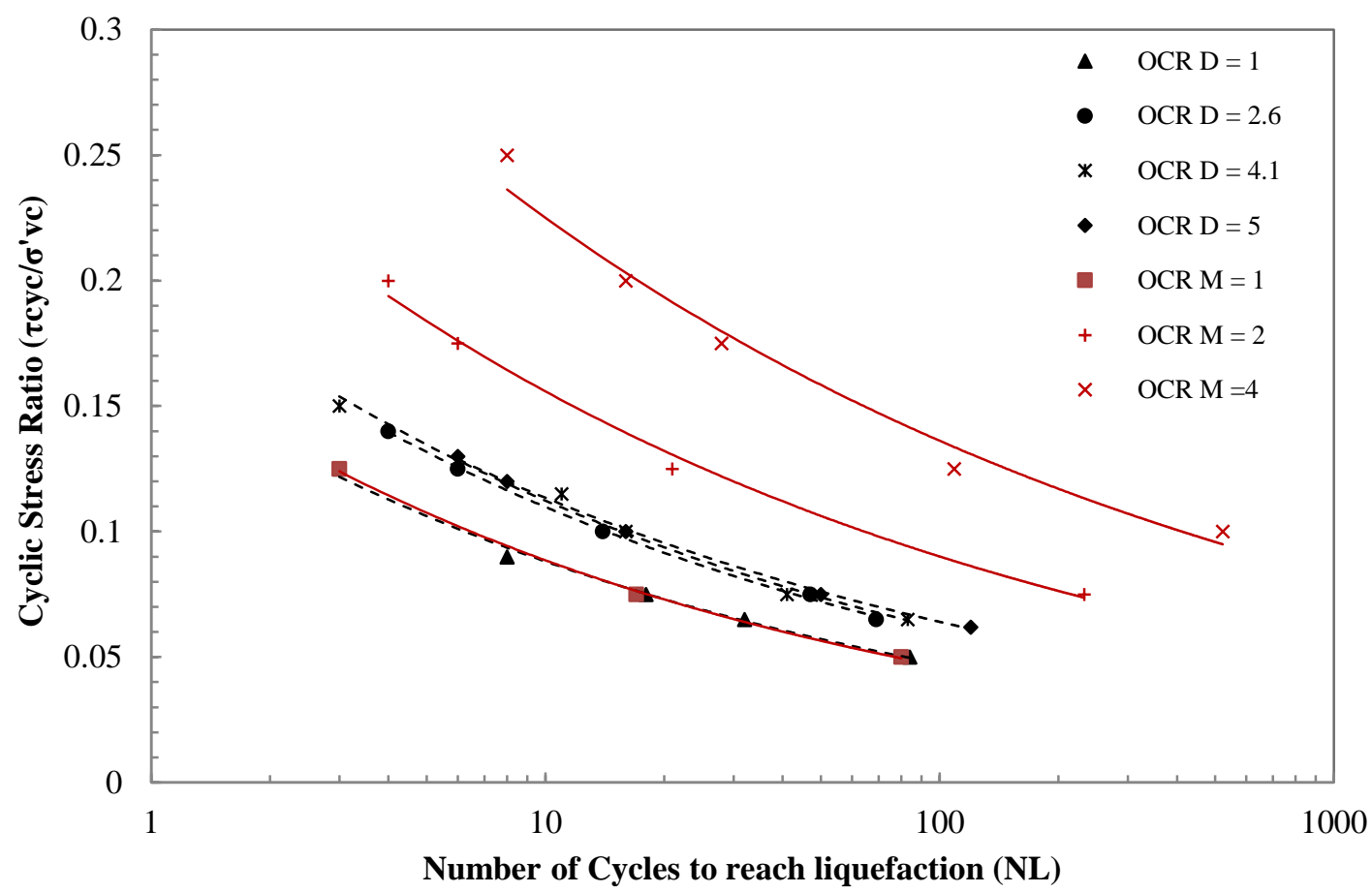

Figure 12 Comparison of monotonic results of $0 \mathrm{CR}_{M}$ and $0 \mathrm{CR}_{\mathrm{D}}$

It is also obvious that there are clear differences between the responses of mechanically over-consolidated and desiccated tailings. While mechanically over-consolidated tailings exhibit a peak under monotonic loading, the desiccated tailings exhibit no peak, but show large strain hardening past the phase transformation point.

The comparison of $O C R_{M}$ and $O C R_{D}$ on CRR of thickened gold tailings are presented in Figure 12. It is obvious that both normally consolidated samples exhibit somehow equivalent responses. It also shows that specimens with higher desiccation history are more resistant to liquefaction in comparison to normally consolidated samples. However, the cyclic resistance of desiccated specimens at different $O_{C} R_{D}$ values are remarkably lower than the resistance curves for $O C R_{M}=2$. This observation is in agreement with the observations under monotonic loading.

In terms of void ratio, the desiccated rewet samples present either the same void ratio (within +/- 0.05 ) or lower void ratios compared to mechanically over-consolidated specimens with the same OCR. Therefore, the stronger response of the mechanically over-consolidated tailings cannot be attributed to differences in density.

\section{$4 \quad$ Summary and conclusions}

The stress history of thickened gold tailings layers was simulated in the laboratory in order to investigate the contribution of desiccation on monotonic and cyclic shear. Mechanically over-consolidated samples (unloaded to $50 \mathrm{kPa}$ before shearing, after consolidation between $50-200 \mathrm{kPa}$ ) were also prepared and compared with desiccated/rewetted samples. Based on these experiments, the following can be concluded:

- Samples of the gold tailings that were allowed to settle, but did not desiccate before consolidation, exhibited a contractive response during monotonic loading. 
- Desiccation up to the AEV could significantly increase the monotonic and cyclic shear strength of these tailings; however, while desiccation beyond AEV did provide additional strength, the increase was marginal.

- While mechanically over-consolidated tailings exhibited a peak under monotonic loading, the desiccated tailings exhibited no peak, but underwent large strain hardening past the phase transformation point.

- Both monotonic and cyclic shear strength increase with desiccation. However, the rate of strength increase for OCRM is significantly larger than for OCR.

- The desiccated and mechanically over-consolidated tailings behave differently, both qualitatively and quantitatively, when comparing samples or similar void ratio. Estimating the contribution of desiccation to strength by using data from a sample mechanically over-consolidated to a consolidation pressure equal in value to the AEV, using the method described in the paper, would overestimate the contribution of desiccation to strength.

\section{References}

Al-Tarhouni, M., Simms, P. and Sivathayalan, S. (2009) Seismic behaviour of thickened gold mine tailings, in Proceedings 12 th International Seminar on Paste and Thickened Tailings (Paste09), R.J. Jewell, A.B. Fourie, S. Barrera, J. Wiertz (eds), 21-24 April 2009, Viña Del Mar, Chile, Gecamin Limited, Santiago, Australian Centre for Geomechanics, Perth, pp. 291-300.

Al-Tarhouni, M., Simms, P. and Sivathayalan, S. (2011) Cyclic behavior of reconstituted and desiccated samples of thickened gold mine tailings, Canadian Geotechnical Journal, Vol. 48(7), pp. 1044-1060.

Bishop, A.W. (1959) The principle of effective stress, Teknisk Ukeblad, Vol. 106(39), pp. 859-863.

Cifuentes, L.A. and Verdugo, R. (2009) in Proceedings 12th International Seminar on Paste and Thickened Tailings (Paste09), R.J. Jewell, A.B. Fourie, S. Barrera, J. Wiertz (eds), 21-24 April 2009, Viña Del Mar, Chile, Gecamin Limited, Santiago, Australian Centre for Geomechanics, Perth, pp. 313-323.

Daliri, F., Simms, P. and Sivathayalan, S. (2011) A comparison of different laboratory techniques to simulate stress and moisture history of hard rock mine tailings, in Proceedings of Tailings and Mine Waste 2011 Conference, November 2011, Vancouver, B.C., Canada., Keevil Institute of Mining Engineering, Vancouver, B.C., pp. 163-175.

Fisseha, B., Bryan, R. and Simms, P. (2010) Evaporation, unsaturated flow, and salt accumulation in multilayer deposits of a paste gold tailings, Journal of Geotechnical and Geoenvironmental Engineering, Vol. 136, No. 12, pp. 1703-1712.

Fredlund, D.G. and Morgenstern, N.R. (1977) Stress state variables for unsaturated soils, Journal of Geotechnical and Geoenvironmental Engineering Division of American Society of Civil Engineers, Vol. 103, pp. 447-466.

Kim, H., Daliri, F., Simms, P. and Sivathayalan, S. (2011) The influence of desiccation and overconsolidation on monotonic and cyclic shear response of thickened gold tailings, in Proceedings 14th Pan-American Conference on Soil Mechanics and Geotechnical Engineering, October 2011, Toronto, Canada, Electronic proceedings (paper 765). Canadian Geotechnical Society.

Lu, N. and Lukos, W.J. (2006) Suction Stress Characteristic Curve for Unsaturated Soil, Journal of Geotechnical and Geoenvironmental, Vol. 132, No. 2, pp. 131-142.

NRC (1985) National Research Council. Liquefaction of soils during earthquakes, National Academy Press, Washington, D.C.

Simms, P., Dunmola, A., Fisseha, B. and Bryan, R. (2010) Generic modelling of desiccation for cyclic deposition of thickened tailings to maximize density and to minimize oxidation, in Proceedings 13th International Seminar on Paste and Thickened Tailings (Paste2010), R.J. Jewell and A.B. Fourie (eds), 3-6 May 2010, Toronto, Canada, Australian Centre for Geomechanics, Perth, pp. 293-301. 
